\title{
Probe into the Humanistic Spirit Contained in the Courses of Science and Engineering in Universities
}

\author{
Wenbing Wu \\ Nanchang Normal University, Nanchang, China \\ Email: wwbysq@fjnu.edu.cn
}

How to cite this paper: $\mathrm{Wu}, \mathrm{W}$. B. (2020). Probe into the Humanistic Spirit Contained in the Courses of Science and Engineering in Universities. Creative Education, 11, 25942598.

https://doi.org/10.4236/ce.2020.1112191

Received: November 9, 2020

Accepted: December 8, 2020

Published: December 11, 2020

Copyright $\odot 2020$ by author(s) and Scientific Research Publishing Inc. This work is licensed under the Creative Commons Attribution International License (CC BY 4.0).

http://creativecommons.org/licenses/by/4.0/

\begin{abstract}
The mission of higher education is to train senior professionals with a sense of social responsibility, innovative spirit and practical ability. Higher education should regard the effectiveness of moral education as the fundamental standard for testing all work in colleges and universities, adhere to the integration of knowledge transfer and value guidance, and the integration of explicit education and implicit education, and fully explore the humanistic and ideological education resources contained in various courses and teaching methods. In this paper, by incorporating the humanistic spirit into the science and engineering courses, while imparting scientific knowledge, it pays attention to cultivating students' discipline and collectivism. The teaching effect shows that this teaching method has a certain positive effect on cultivating qualified talents.
\end{abstract}

\section{Keywords}

Humanistic Spirit, Course Education, Science and Engineering

\section{Introduction}

The training goals of ordinary colleges and universities for undergraduates are: to cultivate senior talents who have a solid grasp of the basic theories, specialized knowledge and basic skills of the subject, and have the preliminary ability to engage in scientific research or undertake specialized technical work. Students are required to have a reasonable knowledge structure, master the general methods of scientific work, be able to correctly judge and solve practical problems, have the ability and habits of lifelong learning, and be able to adapt and be competent in the changing career fields. The teaching of undergraduate education know- 
ledge should not only develop in depth to the subject, but also pay attention to the horizontal relationship between subjects. At the same time, undergraduate education should pay attention to cultivating students' scientific thinking ability, creative ability, innovative spirit and entrepreneurial spirit.

In colleges and universities, subjects other than science and engineering are generally called humanities. It is not accurate.

Knowledge can be roughly divided into three major parts: science and technology, literature and art, philosophy and religion. Science includes mathematics, natural sciences, and social sciences, which are objective, regular, and rational. Literature and art are mainly subjective, emotional and perceptual. Philosophy and religion should be said to be mainly about humanities. Moreover, this kind of humanistic knowledge, humanistic thought, and humanistic spirit have penetrated a large amount of literature and art, and even a large amount of it has been produced in literature and art, and has also penetrated into social science. Therefore, people often regard literature and art, and even social sciences, as humanities. In fact, the humanistic spirit also permeates natural science and technology. But the amount of penetration is closely related to the culture and education of a country. If it is not permeated, such social sciences and natural sciences, even such literature and art, will have no humanities, at least they lack humanities.

This article is based on the requirement to infiltrate the humanistic spirit into natural science and technology, taking the movement of electrons outside the nucleus as an example, to infiltrate the ideas of freedom and discipline into natural science. It is hoped that this teaching method can help cultivate science and engineering students with humanities.

\section{Humanistic Thoughts Contained in the Law of Electronic Movement}

"Personal concept", that is, to recognize and respect the individual, is a philosophical concept in humanistic thinking.

"Personal concept" is John Locke's second great discovery. Respect for the individual first refers to the country, and the government must respect the individual. Powerful institutions respect individuals without power. This is the basic point of humanistic thinking and the basic point of democratic politics. At the same time, respecting individuals means respecting "everyone." As an individual, we must respect ourselves and others. Only by respecting others can we respect ourselves, and only by respecting ourselves can we respect others (Locke, 1955, 2007).

At the same time, "the concept of freedom" is also an important concept in humanistic thinking. To the greatness of John Locke lies in not only proposing a great concept, but also further proposing the institutional guarantee for the realization of this concept. He created a new concept of governing society: not by slogans, but by systems, a system that restricts each other. 
"The concept of freedom" also refers to the freedom of "everyone". Only by respecting the freedom of others can we have our own freedom, strive for our own freedom, and never harm the freedom of others. How to identify and judge whether the freedom of others is damaged? Humans have found a best way: make rules. Formulate rules for the purpose of protecting human freedom. This is the basic concept of the modern legal system, and rules protect human freedom. Therefore, as an individual, violating the rules is damaging the freedom of others, and you have to pay a price and be punished. As an individual, following the rules means respecting the freedom of others and also respecting your own freedom. Therefore, the awareness of rules has become the basic quality of citizens of free countries. Therefore, liberalism is by no means as distorted by some people: do whatever you want.

It can be seen that the "concept of freedom" is not only a powerful weapon against despotism, but also the philosophical foundation of good social morality. Freedom presupposes discipline. Freedom has always been restricted. Unrestricted "freedom" is not freedom, but willfulness and indulgence. In work and life, there is no absolute freedom at all. Any freedom must be based on observing rules and discipline. Discipline is by no means the opposite of freedom. On the contrary, it aims to clarify the boundaries of freedom and encourage people to better exercise their freedom.

The above-mentioned personal concept and freedom concept can be similarly explained in the movement of electrons around the nucleus in natural science.

It can be seen from Figure 1 that there are many electrons outside the nucleus, and their trajectories seem to be irregular. Will these electrons collide? The research of modern physics shows that the movement of electrons seems chaotic, but in fact their movements follow strict laws of physics, and there is no collision between electrons and electrons.

Bohr believes that the orbital radius of the electrons moving around the nucleus can only be a certain discrete value. This phenomenon is called orbital quantization: different orbits correspond to different states. In these states, although the electrons are moving at a variable speed, No energy is radiated, so these states are stable; atoms have different energies in different states, so the energy of atoms is also quantized.

To sum up the above content, Bohr theory has three main points:

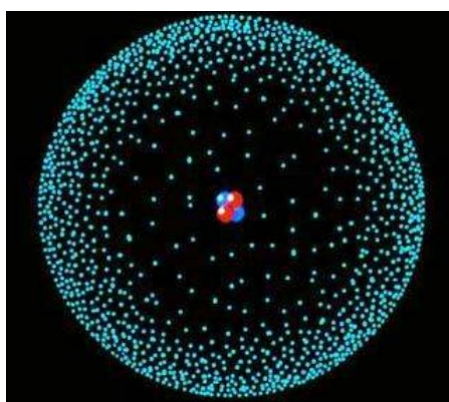

Figure 1. Electronic cloud map. 
1) Atoms can only be in a series of discontinuous energy states. In these states, atoms are stable. Although electrons revolve around the nucleus, they do not radiate energy outward. These states are called stationary states.

2) When an atom transitions from one stationary state (energy E1) to another stationary state (energy E2), it radiates (or absorbs) photons of a certain frequency, and the energy of the photons is determined by the energy difference between the two stationary states, That is, $h v=\mathrm{E} 2-\mathrm{E} 1$.

3) The different energy states of atoms correspond to electrons moving along different circular orbits. The stationary states of atoms are discontinuous, so the possible orbits of electrons are discrete (Bohr, 1928; Bohr, Mottelson et al., 1970).

It can be seen that if an electron goes from one orbit to another, it does not change the radius in the shape of a spiral, but "jumps" from one orbit to another. Bohr calls this phenomenon a transition.

It is precisely because of these physical laws that the electrons outside the nucleus are guaranteed to be distributed in an orderly manner around the nucleus, that is, each electron runs on its own fixed orbit, and the seemingly chaotic movement of the electrons outside the nucleus is also guaranteed. Do not interfere with each other, and there will be no collisions. If each electron is regarded as a person, the movement of electrons outside the nucleus can well explain the relationship between freedom and discipline in human society: each electron can only be guaranteed that it runs on its own orbit according to the law, it will not collide with other electrons. Only in this way can guarantee the freedom of each electron itself and the freedom of movement of other electrons.

\section{Conclusion}

The mission of higher education is to train senior professionals with a sense of social responsibility, innovative spirit and practical ability. From the above analysis, we can see that whether the mathematical principles or the laws of physics, there may be a relationship between freedom and discipline. In other words, everything in nature is restricted by various laws, and absolute freedom does not exist. By introducing the corresponding humanistic principles into the natural science classrooms, students' awareness of rules, discipline, and collectivism can be cultivated, and this teaching method also meets the requirements of college students.

\section{Funding}

This paper is supported by Research Foundation of the Nanchang Normal University for Doctors (NSBSJJ2018014) Key R\&D Project of Jiangxi Provincial Department of Science and Technology (20192BBEL50040, 20192BBHL80002).

\section{Conflicts of Interest}

The author declares no conflicts of interest regarding the publication of this paper.

\section{References}

Bohr, A., Mottelson, B. R. et al. (1970). Nuclear Structure, Vol. 1. Physics Today, 23, 58. 
https://doi.org/10.1063/1.3022342

Bohr, N. (1928). The Quantum Postulate and the Recent Development of Atomic Theory. Nature, 121, 580-590. https://doi.org/10.1038/121580a0

Locke, J. (1955). A Letter Concerning Toleration. Indiana: The Bobbs-Merrill Company.

Locke, J. (2007). Second Treatise on Government. Tredition Classics, 2, 361-363. 